\title{
10
}

\section{Decarbonising Academia's Flyout Culture}

\section{Nicholas A. Poggioli and Andrew J. Hoffman}

\section{Introduction}

Air travel and aeromobility are technologically and culturally central to academic life (Lassen, 2006; Urry, 2002). Academics fly to collect data, speak at conferences, present research seminars, interview for jobs, consult with companies, give government testimony and teach classes (Arsenault et al., 2019). Flying is so prevalent that the academic community revolves around what we call 'flyout culture'. Where culture is 'a pattern of shared basic assumptions' that are 'taught to new members as the correct way to perceive, think, and feel' about being a community member (Schein, 2010, p. 18), flyout culture is a pattern of assumptions that academics share about the role, symbolism and importance of flight to what it means to be a member of the academic community. Academics maintain and reproduce flyout culture by teaching aspiring academics about its centrality and importance as they join the community.

\footnotetext{
N. A. Poggioli $(\bowtie) \bullet$ A. J. Hoffman

University of Michigan, Ann Arbor, MI, USA

e-mail: poggioli@umich.edu; ajhoff@umich.edu 
Flyout culture is so strong that academics report a 'fear of not flying', rooted in the belief that academic success requires flight (Nursey-Bray et al., 2019).

However, flyout culture is facing challenges on multiple fronts. Some now question whether flight is desirable, given growing concerns about carbon emissions and climate change. Pressure from outside academia comes from flight shaming campaigns by groups like Stay Grounded and Count Us In (Count Us In, 2020; Stay Grounded, 2020). Internal pressure comes from academics, especially those working on climate change, who are moving to reduce their quantity of flying and compel others to do the same. These academics are in part motivated by a fear of being accused of 'climate hypocrisy' for expressing concern about carbon emissions but continuing to fly (Dolsak \& Prakash, 2018; Higham \& Font, 2020). In October 2015, 56 scholars from more than 12 countries petitioned institutions and academics to reduce flying-related emissions (Academic Flying, 2015). Since then, increasing numbers of academics are voluntarily avoiding flights (Delmestri, 2019; Nursey-Bray et al., 2019), and at least 73 academic institutions have adopted decarbonisation policies that include reductions in flight travel (ETH Zurich, 2020).

In this chapter, we explore how academia’s flyout culture might change as external and internal decarbonisation pressures intensify. While much prior attention to academia's decarbonisation challenge focuses on its technological aspects, our focus in this chapter is on academic culture, the system of beliefs, assumptions and values that guide academics' behaviour (Bazerman \& Hoffman, 2000). Flight is more than a technological means of moving bodies or objects. It is also a cultural artefact, a 'palpable but hard to decipher' object (Schein, 1990, p. 111) representing shared values and assumptions about its role in the occupational community of academics. As such, we examine the values underlying flyout culture, how they might or might not change and what new values might arise in a decarbonised academy.

We develop our argument in four parts: We first discuss the empirical context of academic aeromobility. Next, we examine flight as a cultural artefact and consider six cultural values attached to it: ideas, efficiency, quality, evaluation, recreation and status. We then outline mechanisms by which flyout culture might change, offering an assessment of possible 
outcomes and adaptations to meet carbon reduction goals. We consider what new values might arise if academia shifts away from aeromobility, and we describe sources of resistance that might maintain flyout culture in its present form. Finally, we conclude by considering how academia might successfully decarbonise and move away from flyout culture.

\section{Academic Flight}

Academics are a professional community with regular access to flight, especially international flight. Only 2-4 per cent of the global population flew internationally in 2018, and 1 per cent of the population produced 50 per cent of carbon emissions from flight (Gössling \& Humpe, 2020). Academics from North America (Arsenault et al., 2019; Klöwer et al., 2020; Wynes et al., 2019), Europe (Achten et al., 2013; Lassen, 2009) and Australia (Nursey-Bray et al., 2019) fly more than academics from other regions, and academics as a profession fly more than most other professions. Academics are likely responsible for a disproportionately large share of society's flight emissions.

\section{The Extent and Impact of Academic Flying}

Academics fly to conduct research, teach, give presentations, perform service activities and network at conferences, seminars and workshops. Arsenault et al. (2019) found that international travel accounted for 83 per cent of professors' annual travel distance, averaging 33,080 kilometres on 7.1 trips per year (3.5 international and likely by plane). Postdoctoral students averaged 4.6 trips per year (1.5 international) and 13,590 kilometres travelled. Graduate students, staff and undergraduates travelled less frequently and fewer kilometres, with fewer international trips. At the University of Adelaide, 85 per cent of faculty flew at least once in the previous year, and 22 per cent flew more than five times (Nursey-Bray et al., 2019). Wynes et al. (2019) found that 60 per cent of flights in a sample of University of British Columbia faculty were for 
conferences, 16 per cent fieldwork, 6 per cent university business, 5 per cent lectures and 13 per cent other purposes.

Academic flying emits greenhouse gases that contribute to climate change. Flying and the associated carbon emissions are endemic to the academic enterprise. Both flight frequency and carbon emissions increase with years in academia, salary and position rank. Full professors emit 7.52 tonnes of carbon dioxide equivalents per year, associate professors 5.40 tonnes, assistant professors 2.49, postdocs 2.49 and graduate students 2.44 (Wynes et al., 2019). Producing a four-year PhD thesis generates 21.5 tonnes, with travel contributing about 75 per cent of the emissions (Achten et al., 2013). Producing an undergraduate degree generates fewer carbon emissions because undergraduate students fly less (Parsons, 2009). Flights per year increase with an academic's age, peaking in the 41-50-year-old bracket (Lassen, 2009).

Despite these trends and a fear of not flying, Wynes et al. (2019) found no association between flying and metrics of academic performance like citation counts or H-index. Cultural values and beliefs more than empirical evidence perpetuate flying within academia. Flyout culture is becoming a focus of increasing interest as universities face mounting pressure to meet climate change mitigation targets by decarbonising their operations (ETH Zurich, 2020).

\section{Pressures to Decarbonise and the Role of Flying in Those Efforts}

Academic institutions are under growing pressure to decarbonise by achieving carbon neutrality, divesting fossil fuel-related institutional investments and increasing energy efficiency. Climate hypocrisy charges have been levelled across the spectrum, against both individuals and organisations and against those both inside and outside academia; anyone who speaks out on climate change is vulnerable. In 2007, the Tennessee Centre for Policy Research charged that environmental activist Al Gore's 20-room home and pool house used more than 20 times the national average kilowatt-hours of energy (Tapper, 2007). In 2017, the National Centre for Public Policy Research timed similar criticism to the 
release of Gore's An Inconvenient Sequel movie about climate change (Bond, 2017). Critics targeted Google in 2019 for hosting a climate change summit whose scientists, celebrities and leaders arrived in 114 private jets (Haas, 2019). Even the 2015 Paris Climate Talks were criticised for creating 300,000 tonnes of travel-related carbon emissions (Stockton, 2015), including accusations that attendees were 'hypocrites in the air' (Anderson, 2014). Critics claimed 'any climate "activist" who isn't absolutely at home on Webex and GoToMeeting is a complete phony', and that 'they should be living entirely "off the grid" if they truly walked the talk' (Worrall, 2015).

Pressure for change is also emerging inside academia. Climate scientists report feeling dissonance about working at institutions that lack carbon reduction goals (Higham \& Font, 2020) and worry about losing their credibility if they fly (Sparkman \& Attari, 2020). Some academics encourage colleagues to travel by train or bicycle (Delmestri, 2019), and journal editors call on peers to fly less (Nature Nanotechnology, 2019). These efforts include calls for 'slow conferencing' and 'slow science' (Berkowitz \& Delacour, 2020; Ruddick, 2019). Professor Laurie Zoloth, director of Northwestern University's Centre for Bioethics, Science and Society, recommends scholars skip conferences every seven years (Oppenheimer, 2014). Activist Greta Thunberg captured the reputational need to give up flying: 'It would be much more useful for me to fly around the world advocating for climate action. But it's all about sending a signal that we are in a crisis and that in a crisis you change behaviour' (Marchese, 2020).

In summary, internal pressures, climate change goals, the desire to maintain legitimacy with external communities and growing comfort with virtualised communication suggest that academia is in a state of change and that an opportunity to reduce academic flight is at hand. But such a shift will create tensions within academic culture by challenging explicit values and implicit assumptions of status, career advancement and community identity. Some will resist change while others will embrace it, triggering a contested debate over the role of flight in academia, the values it represents and the emergence of new values to replace them. To understand where such changes might lead academia, we present six values that underlie academia's current flyout culture. 


\section{Six Values of Flyout Culture}

Flyout culture refers to values, beliefs and assumptions about flight shared by members of the academic occupational community (Hoffman, 2001). In that community, flight is a cultural artefact to which members attach deeper values, similar to how professionals attach values of globalisation to the suitcase artefact (Durante, 2016). Such values are both espoused, explicit statements of behaviour norms, and tacit, implicit underlying assumptions about behaviour norms (Schein, 2010).

We identify six values academics attach to flight: ideas, efficiency, quality, evaluation, recreation and status. We recognise this as an incomplete list of values. Our objective is to examine the most prominent and salient values of flight, not exhaustively identify all values. We also recognise there is some blurring between the act of flying and the set of activities enabled by flight, like presenting a research seminar. Flight enables these activities, which are part of the 'flyout', so we include them in our analysis.

\section{Value of Ideas}

The value of ideas captures beliefs and assumptions about how knowledge is created and shared in academic work. It holds that idea generation through in-person communication differs from distanced channels like mail, email, telephone and video conference. Academics generally view flight as advantageous, perhaps even necessary, for generating new ideas. Surveys show that the most common purpose that academics assign to flight is idea generation, especially attending conferences or meetings to present or conduct research (Arsenault et al., 2019; Lassen, 2009; NurseyBray et al., 2019). Studies suggest the strength of this belief by asserting that 'the flow of knowledge is closely linked to proximity' and that 'going to a conference alters the creation of collaborations' (Chai \& Freeman, 2019, p. 2138).

The value of ideas involves a belief that in-person exchanges transmit more than data and knowledge by allowing relationship formation and renewal. Relationships are formed through prolonged and associated engagements outside the formal seminar presentation, and renewal and 
maintenance of those relationships occur at in-person conferences, meetings and classrooms as academics and students present new ideas, evaluate the ideas of others and defend their ideas against evaluation. These continued interactions form the basis for ongoing idea generation that often takes place in informal settings like dinners, coffee, walks or drinks.

\section{Value of Efficiency}

Closely related to the value of ideas is the value of efficiency. Travel allows scholars to develop networks through which they can access information, transmit their knowledge and increase their status position within certain scholarly networks. Such networking activities, in fact, are intimately linked with air travel (Lassen, 2009). In such activities, smaller group discussions or one-on-one meetings allow the exchange of exclusive knowledge about important career choices such as the latest research and research questions, the future trajectories of publication interests or the awareness of research communities and their relative status. Flyouts can be highly efficient for attaining this information. For trips beyond a certain distance, no transportation mode compares to the rapidity of flight to enable face-to-face interaction. The comfort and setup of flight also allow academics to work while travelling by writing or reading on the plane. On this dimension, flight shares a characteristic with train travel and, to a lesser extent, bus and car travel as a passenger.

\section{Value of Quality}

Through such exchanges as described earlier, academics often use flights as a signal of the quality of colleagues and their work. (The next section on the value of evaluation deals with the role of flight in evaluation processes.) Signalling theory suggests that when quality is difficult to observe, evaluators substitute more easily observed characteristics they believe positively correlate with quality (Connelly et al., 2011). Flyout culture holds the belief that the number of flyouts a person takes and the destinations of those flyouts positively correlate with quality. This assignment of 
quality begins with doctoral students as they enter the job market; signals of their desirability can be measured by the number of 'flyouts' that they are invited to accept for interviews. Most schools know what other schools have extended a flyout offer to a candidate, and perceived candidate quality goes up with the number and status of the schools.

Quality signals continue as academics advance in their careers. Flyout culture treats destination prestige and colleague quality as interrelated and believes the quality of a scholar's work is positively correlated with the status of schools they visit. Relatedly, the status of scholars who accept flyout invitations signals the quality of a school or professional group. A colleague can have his/her reputation enhanced by being invited to speak and becoming a singular centre of attention through repeated meetings and engagement. People will make assessments about someone's reputation, not only by their work but by measures of who else deems their work to have high quality.

\section{Value of Evaluation}

The value of flyouts can be codified in evaluative metrics of the academy. Annual reviews ask scholars to report the number and status of speaking invitations (whether by the organisation extending the invitation or the form of the engagement - a keynote address or invited talk is 'worth more' than accepted papers at a conference, and those are worth more than talks at practitioner conferences). Many scholars list speaking destinations on their résumés. Schools then use such information to measure the status of the scholar for hiring, pay raises, promotion and tenure.

Evaluation can also take the form of other metrics of rewards, such as speaking fees, invitations to teach in executive education or admission to exclusive events with high-status invitees in private meetings. Doctoral students can also find themselves evaluated by flyouts as the availability of funding to attend select meetings and gatherings can be granted as a reward for excellent research or other signals of merit. Conversely, the opportunity to conduct research fieldwork, attend conferences and meetings and present research in select formats will be used to evaluate the 
strength of the graduate as well as the programmes in which they are trained. Then, once on the job market, this evaluation process continues with the criteria of merit being the number and quality of flyouts for having made the shortlist of candidates to visit the hiring institution on a flyout. Academics believe flyouts and the in-person interactions they enable provide the hiring institution qualitatively different, and better, evaluations of candidates than virtualised visits would provide.

\section{Value of Recreation}

Not only are flights a valuable functional aspect of academic life, they also serve a recreational aspect as well, providing both professional and leisure benefits and opportunities to travel to desirable global cultural, political and tourism centres and often without paying the full cost of travel, called 'conference tourism' (Høyer, 2009; Høyer \& Naess, 2001). Work and travel decisions are highly individualised with such associated benefits weighing heavily in decisions on whether to travel or not (Lassen, 2009). Academics often extend professional trips by several days or weeks to combine professional travel with tourism, sometimes bringing family members. Conferences and meetings held in tourism centres are more attractive to attend than events in places less desirable as tourism donations. Many conferences draw significant attendance and establish higher status by being held in desirable locations: a meeting in Paris, Tokyo, Beijing, London, Asilomar (on the Pacific Coast) or the Greek Islands, for example, might draw more interest and therefore more prestige than a conference in a small town far from an airport or in a colder climate. Flyouts can even create and reinforce the status of an academic institution by assessing the quality of the nearest airport and combining that assessment with a travel budget that allows greater ease to travel. Our own institution, the University of Michigan, prides itself on the extensive reach of Detroit Metro airport and its direct connections to global destinations like London, Rome, Tokyo and Beijing. Colleagues at other institutions near Chicago's O'Hare airport, London's Heathrow airport and Tokyo's Narita airport report similar esteem for their convenience. 


\section{Value of Status}

Global travel is part of the global elite cosmopolitan academic identity with nearly unlimited mobility privileges, combining flyouts with numerous values that personify status. The institutional trappings are significant. Junior flyouts take the form of conference presentations, job market talks or invited seminar presentations, which indicate career progress, career potential and labour market attractiveness, contributing to how a junior academic's status, prestige and market desirability are constructed. Senior flyouts include speaking 'gigs' in the form of talks, seminars and other events like serving as a keynote speaker, sitting on a panel discussion and delivering a commencement address. Academics interpret the number of senior flyouts as related to leadership and influence in the field. A certain aura can develop around a professor who is in "high demand' for their research presentations and their presence.

The external trappings of travel signal status are no less significant, such as airline frequent flyer programmes (i.e. 'achieving status'), elite membership in car rental services and hotel rewards programmes, all of which shorten check-in times, extend special benefits and can be visibly broadcast to others (i.e. first-class flight upgrades). All of these trappings communicate stature to peers as a means of ordering themselves against one another in the status hierarchy as it presently exists and tends to reproduce and reinforce that hierarchy (Espeland \& Sauder, 2007). Overall, travel signals the independence and freedom of the community of academic scholars both on its own and in relation to other professions.

\section{How Flyout Culture Might Change}

As decarbonisation efforts lead to a decline in academic flying, a transformation in flyout culture will have both technical and cultural elements. Indeed, one might argue that academia is in the midst of a punctuated shift in cultural equilibrium (Gersick, 1994; Kuhn, 1962; Romanelli \& Tushman, 1994). New travel modes are being considered as replacements 
for air travel. Combined with efforts to virtualise more elements of education and research delivery, the importance of flight confronts a challenging emergent reality in which many of the activities thought only possible through flight become possible by other means or are simply viewed as less desirable. This decline in desirability will be reflected in the obsolescence of some flyout culture values, beliefs and assumptions and the emergence of new cultural arrangements that will reform the foundations of academic life.

In this section, we consider four changes associated with reducing academic flight. Though not mutually exclusive, we present them in order of least to most culturally disruptive-buying carbon offsets; shifting travel modes; centralised, infrequent or slow conferencing; and virtual communication-and examine how each change reinforces or undermines the existing values of flyout culture.

\section{Buying Carbon Offsets}

The least disruptive change to flyout culture might come from carbon offsets that provide a technological and economic means of decarbonising the effects of flight. A carbon offset matches a flight's carbon emissions to an equal or greater amount of carbon absorption, resulting in the combined flight and offset contributing zero or negative emissions to the atmosphere. Some universities allow scholars to purchase offsets through internal carbon reduction exchanges or on open exchanges connecting emitters to absorbers (Janisch \& Hilty, 2017).

Carbon offsets offer the promise of solving flyout culture's emissions problem without requiring any change to flying behaviour. For those able to offset their emissions, the values of ideas, quality, recreation, evaluation, recreation and status remain unchanged as flights continue unchanged. As a result, offsets might favour more affluent academics and institutions who can continue carbon-intensive flight activities while claiming to purchase away their impacts.

However, even if the purchase of offsets become an effective means of decarbonising academic flight, the change could challenge some dimensions of flyout culture values by increasing the information available to 
evaluate flight consumption. Notably, offsetting requires an accounting system linking emission to absorption. Such data could create new flight consumption measures that become integrated into academia's values of quality and status. The amount of offset emissions could become a new status symbol used in institutional rankings. Institutions might publish emissions data like some publish salaries, publications or service to the community, leading to social comparisons between academics and institutions. Academics who fly but do not provide evidence of offsetting might be seen as lower-quality scholars. While this might first affect climate change researchers seeking to avoid charges of climate hypocrisy, pressure on institutions to disclose emissions could require all academics to disclose emissions. Tonnes of offset emissions might be added to other debated quality metrics like citations, travel status on airlines and access to other perks associated with high consumption of global air travel. Similarly, individual academics may be less inclined to broadcast airline flight status as such 'status' may be viewed in a more negative light.

\section{Shifting Travel Modes}

A second response to decarbonisation pressure is substituting flight with less polluting travel modes. Professor Kevin Anderson at the University of Manchester took a train to a conference in China, convinced this added to the legitimacy of his science (Hoffman, 2016). Professor Giuseppe Delmestri from the Vienna University of Economics and Business demonstrated a commitment to bicycle by riding 830 kilometres from Vienna to attend a conference in Milan (Delmestri, 2018) and helped organise a conference by train initiative in 2019 (Delmestri, 2019). Social media campaigns like \#NoFly2020 urge academics to eliminate their use of airplanes for all of 2020. However, substitution is not always an emissions solution. Long-distance train travel in Canada emits more carbon per passenger than flying because trains have low passenger capacity and declining ridership, travel significantly longer distance on fixed track compared to direct-route flights and have outdated diesel engine technology, all fixable problems (Katz-Rosene, 2020). 
Changing travel mode could alter the flyout culture value of efficiency as some begin to see travel by train as more efficient than flight. Trains provide a more comfortable environment than planes for work or leisure while travelling. If slower forms of travel become more common, academics may seek out trains for certain length trips for the comfort and opportunity to be more productive or more relaxed with the travel time.

Shifting travel modes might also change the value of recreation. Travelling to a city centre, boarding a train and emerging in another city centre could become more attractive than travelling to an airport, boarding an airplane and emerging at another airport. What academics view as valuable recreational opportunities enabled by the profession could shift away from global flight-based tourism to local tourism prioritising regional identity and experience diversity. Travel could become a recreation rather than a means of arriving at recreation.

Finally, the value of status might change to ascribe higher status to academics who use slower travel modes. The current value of status views academics who constantly travel as being of higher status than those who do not, implying flyout culture assigns lower status to alternative uses of time like family, community participation, rest and leisure. As non-flight travel modes become positive and desirable, the value of status could begin to see plane travel as primarily consumed by early career, low-status researchers who must fly to network. The current empirical pattern of flight emissions increasing with academic rank could reverse, with higher academic rank becoming associated with more leisurely non-flight travel (Arsenault et al., 2019). These changes could affect institutional status by ascribing higher status to places with robust inter-modal transport options and tighter density with other academic centres.

\section{Centralised, Infrequent or Slow Conferencing}

Conferences are a major source of academic flight emissions. The entire carbon footprint of the 2020 online meeting of the European Astronomical Society was 3000 times smaller than just the travel-related footprint of the 2019 in-person meeting (Burtscher et al., 2020). The 28,000 attendees of a fall 2019 conference emitted 3 tonnes of emissions per person 
(Klöwer et al., 2020), more than the yearly per capita emissions in all but 18 countries (Union of Concerned Scientists, 2020). Conference attendance accounted for about a quarter of the emissions used to produce a four-year PhD graduate (Achten et al., 2013). All of these conferencerelated emissions could be reduced by up to 90 per cent by centralisation, decreased frequency and increased virtual attendance options (Burtscher et al., 2020; Janisch \& Hilty, 2017; Klöwer et al., 2020).

Changing conferences would change flyout culture values. The value of efficiency could change as one can attend far more sessions, present more talks and hear more presentations if there is no travel time to attend the conference and no travel time to move from one session to the other. Further, online conferences allow people to attend from great distances without the time and cost of flying, thereby increasing the diversity of ideas that are shared and attendees that share them. The value of recreation could also shift as academics begin to disentangle work and recreation and seek tourism as a specific activity that can be increased if less time is devoted to working travel. The value of region-based activities might increase as that of global activities decline.

\section{Virtual Communication}

The last change to flyout culture comes from virtual communication technologies that decrease temporal and geographic distance. The emergence of massively open online courses (Whitaker et al., 2016) and sudden virtualisation of curricula in response to the COVID-19 pandemic show the potential for virtual communications to replace in-person activities that currently require flight, such as conferences, invited lectures and guest speaking opportunities.

Virtual communication could reshape the values of ideas, efficiency, evaluation and status. Academics are finding they can attend virtual conferences and form and renew relationships as they did in-person, albeit in different ways. Virtualised coffee chats, panel discussions and informal gatherings offer new forms of relationship maintenance and idea generation, eroding assumptions that in-person interactions offer the only option for high-value engagement. In-person interactions might be seen 
as more limiting because they require more time and offer fewer connection opportunities than virtual engagements.

Virtual communication could also alter the value of efficiency by reconfiguring expectations about resource use. Virtually presenting conference papers might lead academics to reconsider whether it is efficient to use multiple days and thousands of dollars to give a 20 -minute conference presentation. In-person presentations could be seen as profligate resource use.

The value of evaluation might change to accept and even prioritise virtual over in-person processes. Rather than have faculty attend an inperson presentation by a job candidate, the candidate might be asked to submit a pre-recorded video that faculty watch asynchronously. The ability of academics to teach through virtual platforms might increase and even overtake in-person skills. These shifts in the value of evaluation could alter the selection environment for candidates and, over time, change the profession's demographic and skills composition away from in-person charisma and towards online skills.

The value of status could change to place more emphasis on the number of virtual speaking engagements and the number of attendees. A physical room is limited by the number of seats, fire codes and accessibility. Virtual rooms have fewer capacity constraints. The metric of status could yield a step-change in audience size for virtual events as opposed to in-person events. Further, 'global' presentations could become more available to a broader set of scholars as virtual communications decrease or even eliminate the constraints of geographic distance. A virtual presentation to scholars in Mumbai would be just as easy as a virtual presentation to scholars in New York, no matter where the presenter resides. The value of status might also begin to reflect consistency in actions with respect to climate change. Scholars who are excessive flyers might be viewed as climate hypocrites and suffer status discounts, while those who take strong stances on climate change and display a commitment against emissions-heavy flying could be ascribed higher status (Sparkman \& Attari, 2020). However, it should be remembered that virtual communication is not carbon-free. An online search using the Google engine releases 1-10 grammes of $\mathrm{CO}_{2}$ (Quito, 2018). Virtual communications 
yield a variable amount of emissions depending on parameters like bandwidth, video or audio use and screen type: a high-definition video call emits 14 times more carbon than a telephone call (McGovern, 2020).

\section{What New Values Might Arise?}

Now that we have addressed how existing flyout culture values might change with decreasing flight, we turn to four new values that might arise with a shift away from aeromobility: localism, climate concern, emissions transparency and verification. The emergence of these values has the potential to accelerate the shift within academia away from flyout culture and towards a new constellation of values, beliefs and assumptions that are appropriate for and compatible with planetary decarbonisation.

\section{Value of Localism}

A value of localism could emerge with a shift away from flight to distant locations and cultures. Localism would instead appreciate and elevate nearby or regional characteristics. While some academics report that access to an international airport makes a town or city a more desirable place to live, beliefs and assumptions about quality, recreation and efficiency may begin to favour slowness over rapidity and localism over globalism. Rather than an airport making a town attractive, perhaps its surrounding communities will become more important. Flyout culture assumes that flight offers an escape from places viewed as less desirable to live and recreate. More places might become seen as high-quality places you do not have to leave for recreation.

The rise of a value of localism could lead to growth or rejuvenation for regions demoted by flyout culture's focus on global tourism centres. A value of localism might allow academics to choose where to live based less on proximity to work and more on characteristics like recreation opportunities, infrastructure, health and other currently discounted characteristics. These changes could see the rise of a value of localism that looks quite different from flyout culture's present focus on global academic 
nomadism, both in terms of the expectation that academics move anywhere they can secure employment and that they extensively travel to academic events throughout the year.

\section{Value of Climate Concern}

Decarbonisation pressure arises from organised concern about the ongoing and potentially devastating impacts of anthropocentric climate change. This organised concern could manifest as a value of climate concern within academic culture. Some academics are already trying to build such a value by advocating increased use of alternative transportation modes (Delmestri, 2019). Nature Astronomy published a special issue on astronomy's contributions to climate change (Nature Astronomy, 2020) calling on astronomers to address their contributions to climate change (Stevens et al., 2020). A value of climate concern could transform how academics think about the linkages between the nature of academic work and the impact of that work on the global climate. This could elevate attention to academic impacts on the climate-and the climate's impact on academia (Clery, 2020) — to a higher level of priority within the community.

\section{Value of Emissions Transparency}

As decarbonisation leads to more ways of collecting and monitoring carbon emissions data linked to academic work, academics and academic stakeholders may build reporting mechanisms to publicise emissions information. A value of reporting might emerge that elevates the importance of emissions transparency as a necessary step towards decarbonisation. In much the same way that the US Environmental Protection Agency's Toxic Release Inventory compels companies to reduce pollution by mandating that they disclose emissions to land, water and the air, demand for public displays of flight consumption and carbon emissions could inspire institutions to disclose those emissions and increase efforts to reduce them. The emergence of a value for emissions transparency 
would mirror growing attention to the need for environmental, social and governance reporting standards within the corporate sector (Cort \& Esty, 2020). Transparency advocates believe reporting leads to practice improvement, though some claim that the novelty and complexity of climate change mean transparency will not provide markets all the information they need to reallocate resources away from carbon-intensive activities like flight (Kedward et al., 2020). However, whether transparency would solve the problem does not necessarily matter to whether a belief in transparency and reporting could emerge with decarbonisation efforts, especially if carbon offsets and other information-based mechanisms become widespread.

\section{Value of Verification}

The emergence of a value for emissions transparency might correspond with and inspire the rise of a value of verification that would assess the accuracy of what institutions and academics report about emissions. Third-party auditors verify corporate financial statements and, increasingly, environmental, social and governance (ESG) reports. Universities could find that they must verify their emissions reductions to remain legitimate and competitive with peers. Where firms sometimes greenwash their activities by making deceptive or misleading claims about performance (Delmas \& Burbano, 2011; Munshi \& Kurian, 2005), universities may face similar suspicion about their efforts to address climate change, which could spur a value of verification based on the belief that decarbonisation claims require independent validation. The field of accounting, which studies the complex global system of verification for business financial reporting, is beginning to grapple with how to construct a system to verify corporate sustainability claims (IFRS Foundation, 2020). A similar system could emerge with a value of verification and academic decarbonisation. 


\section{What Might Be Gained and What Might Be Lost}

Given the centrality of flight and aeromobility to current academic practice, any change in flying behaviour would meaningfully change academic culture. To explore why, we consider one solution to academic carbon emissions that is becoming increasingly popular and likely: carbon offsets. Many hope offset programmes will allow flyout culture to persist unchanged, potentially moving academia off carbon emissions without significant cultural change. Yet organisations already face criticism of 'offsetting green guilt' by focusing on offsets to achieve carbon reduction or neutrality targets (Kotchen, 2009). As a result, even with offsets we would expect some degree of change in flying to occur and wish to consider what might be gained and what might be lost for the academic identity and culture. We consider the implications in two scenarios-if academics fly more and if academics fly less.

What if academics fly more? If carbon offsets decouple flight from carbon emissions, academics might fly more but emit less carbon. Institutions and academics might gain new programmes funded through offset revenue. Duke University channels offset revenue into tree planting, benefitting residents of the University's home town (Duke University Office of Sustainability, 2020). However, the opposite might occur if offsets pump emissions underground rather than store carbon in plants. Airport and other infrastructure expansion projects could continue destroying habitat, eliminating social benefits of natural spaces. If offsets become expensive, increased academic flight could intensify existing inequities between academics with resources and those without. Lessresourced institutions and academics might face slower career progression and lower survival rates in the profession.

If academics fly less, the primary gain would be reduced or eliminated carbon emissions from academia, helping prevent additional negative climate change impacts, protecting institutions from negative reputation effects from being targeted by decarbonisation advocates and protecting academics from charges of climate hypocrisy (Dolsak \& Prakash, 2018; Higham \& Font, 2020). Shifting away from flyout culture would also enable academics to align their personal carbon values and commitments 
with those of their profession, perhaps increasing work satisfaction and productivity.

A second gain of decreased flight could be increased health benefits for communities impacted by emissions and flyers themselves. The environmental justice movement in the United States highlights how highpolluting infrastructure like airports and oil refineries that produce jet fuel tend to be located in lower-income communities (Fleischmann \& Franklin, 2017; Katz, 2012). These facilities increase asthma and other air-quality-related diseases in nearby communities and affect psychological well-being through noise and light pollution (Cohen \& Kantenbacher, 2020). Research on the health benefits of reduced flying for fliers is less developed and considers possible negative health impacts of increased radiation exposure from flying high in the planet's atmosphere (Barish \& Dilchert, 2010).

Finally, reduced academic flight could lead to greater access to and inclusiveness within academic careers. A focus on aeromobility and multi-day air travel create a selection environment favouring those who can physically travel through flight infrastructure and have social and economic means to be away from home for extended periods. Reducing the need to travel by air could help diversify academia by becoming more welcoming and supportive of people who cannot travel, dislike flight and time away from home, do not have the means to be away from home, cannot afford flying or choose to live a lifestyle emitting fewer emissions than possible with flying.

But reduced flight and flyout culture could mean academia also loses some characteristics. One loss could be the global cosmopolitan identity, replaced by a rise to prominence of regional identity (Beck, 2002). The global cosmopolitan identity links academics into a community that transcends some place-based restrictions, contributing to academic freedom. The decline of flight could undermine academic freedom by relinking research and teaching to idiosyncratic location pressures. As institutions and academics become more grounded in regional political, social and economic contexts, policymakers, businesspeople and other stakeholders might assert more influence on academic work. 


\section{How Flyout Culture Might Resist Change}

Cultures maintain stability and resist change, especially rapid change. Basic assumptions can benefit organisations and individuals by allowing rapid reaction to familiar environmental changes, but they can limit action in response to novel changes like decarbonisation pressures. Given the success of the climate denial movement in preventing policy change to reduce carbon emissions (Oreskes \& Conway, 2011), we should be cautious about whether flyout culture will change to reduce flying. Basic assumptions about organisational procedures, 'how things are done here', and the realities of the external environment can become rigidly emplaced and difficult to alter. Change involves unlearning past accepted ideas and invites resistance from institutions and individuals with vested interests in the status quo. Academia presently lacks powerful cultural processes and routines to respond to decarbonisation, potentially inviting resistance to change rather than creative solutions. This section considers six factors that might inspire resistance: habitual routine, resource limitations, communication breakdowns, fear of the unknown, threats to established power bases (Hoffman, 2000) and an over-reliance on technology.

Stability in patterns of thought and action can be perpetuated by habitual routine. Often the perpetuation of habit stems from an individual's realisation that changing what has become established will involve some form of short-term costs. While inefficient or inconsistent with long-term objectives, these established routines can become familiar, comfortable and reliably predictable. For example, many academics have a highly routinised habit of flying to attend holidays with family.

Resource limitations can restrict the ability of an organisation to overcome sunk costs in equipment, processes and personnel. They can become psychological roadblocks which bias people away from certain actions or responses to demands for change. Successful academics could resist technological change they see as unnecessary (such as new platforms like Zoom, Slack, WebEx and the vastly increasing array of online options), slowing adoption by others. Short-term demands may deny the individual academic any opportunity to consider long-term gains, which 
although they may be encouraging, are only potential. Short-term costs predominate, thus biasing academics and administrators to over-discount the future.

Interdepartmental communication breakdowns can perpetuate environmentally inefficient routines. In the face of possible cost benefits, established reward and incentives systems within organisations often mask the opportunities available through change. For example, reductions in flight may create costs for an individual scholar's normalised work routines while the benefits of such activities in the aggregate may accrue to central administration in its efforts to publicise reduced carbon emissions. However, while central administration may seek to induce such behaviours, their scope of control is quite limited.

Fear of the unknown can drive organisational inertia and the continued reliance on basic underlying assumptions. Both external and internal change can be upsetting for organisational constituents, particularly when the outcome or consequences of change cannot be predicted. Outcomes or consequences can never be predicted. At present, many academics report a fear of not flying based on the belief that professional success requires flight-enabled activities, primarily conferences (NurseyBray et al., 2019); an overriding belief that 'technology cannot fully replace the power of direct interaction' that enables trust- and commitment-building among colleagues and more efficient, potentially less contentious group decision-making processes (Janisch \& Hilty, 2017); and a pervasive fear of missing out on professional opportunities if they give up flight and professional rivals do not.

Finally, threats to established power bases can cause resistance to organisational changes. Culture establishes a structure of power which will bias the perspectives of those who benefit from the existing system benefits. Alterations in the structure and roles of the individual actors may be competence enhancing for some and competence destroying for others. As flight increases with academic seniority and years in academia (Lassen, 2009; Wynes et al., 2019) a lack of leadership and modelling by post-tenure scholars holding powerful institutional positions may undermine efforts at flight reduction and could maintain flyout culture. Because voluntary flight reduction is not guaranteed, decarbonising academia likely requires institutional and political reforms, such as policies against 
reimbursed flight and new reward systems that promote flight avoidance. Further, pre-tenure academics who voluntarily reduce flight in the absence of policies could be dismissed as 'activist' (Stenhouse \& Heinrich, 2019).

Rather than reduce flying, many within flyout culture might seek a technological solution that decouples flight from carbon impacts. Such a belief in techno-salvation is one of the psychological barriers to individuals changing their behaviour to address their carbon emissions (Gifford, 2011). Academics might believe that carbon-free aviation fuel will eliminate flyout carbon emissions, or carbon capture and sequestration technology will solve climate change without people needing to change their behaviour. These solutions are theoretically attractive but currently impractical. Carbon-free aviation fuel is unlikely to be available in needed quantities for decades, and capture and sequestration technology remains unprofitable and too small in scale to meaningfully affect climate change. Finally, advocating for these solutions raises the problem of moral hazard where academics continue flying or fly more, believing technological solutions will make up for their carbon emissions at some unspecified future time.

\section{Conclusion}

While inertia and resistance to change are commonly studied aspects of organisational and institutional life, we prefer to end this chapter on a positive note by considering how academia might successfully reduce or eliminate carbon emissions from flight. We frame this discussion around changes brought on by the outbreak of COVID-19 in 2020. COVID-19 presents us with a cultural discontinuity and what Kuhn (1962) refers to as 'revolutionary science', a period where it is possible to explore alternatives to long-held, taken-for-granted assumptions about how to produce knowledge. In this period of discontinuity, social change agents become engaged in a battle over a new set of assumptions that will replace the old. New assumptions about academic work were already being developed prior to COVID-19 in response to climate change. While the problem of COVID-19 could disappear with a vaccine or other effective 
countermeasure, the problem of climate change will not disappear with a single solution. And any vaccine or countermeasure will arise from coordinated activity. The same must happen for a solution to climate change.

Pandemic responses have shown how quickly some organisational communities, including academia, can eliminate flight and continue working. At the time of this writing (November 2020), the COVID-19 pandemic has sharply reduced flight and aeromobility and hastened the adoption of online and digital communication. By April 2020, daily global emissions were 17 per cent below the 2019 average, and peak average country-level emissions were 26 per cent lower than 2019 (Le Quéré et al., 2020). Most academic travel ended in early 2020. Universities and colleges rapidly switched curricula to online delivery. Faculty, instructors and staff began interacting virtually, including attending conferences, presenting seminars and conducting research. It is unclear whether emissions reduction will be maintained. Some academics could press to return to past flying practices once the pandemic ends, or even before. However, others in the community might advocate for the maintenance of travel reductions and for new behaviours like slow conferencing and virtual communication to become the new academic culture. The COVID-19 pandemic presents a challenge and an opportunity to adapt to a 'new normal' involving less flight.

And, as the adaptations to COVID-19 continue, the new behaviours that have been adopted will become more strongly implanted within academic culture, creating its own form of inertia should COVID-19 restrictions eventually be lifted. Many academics will have become adapted to a lifestyle where presentations can be conducted without multi-day trips and are instead conducted from their home office or living room. Others have become habituated to a lifestyle that increasingly values home life and local engagement over the pressures of flying. In short, the longer the COVID-19 pandemic persists, the more likely that the adjustments of the 'new normal' take hold.

And with those adjustments, a corresponding set of new values will diffuse and gain acceptance. In the end, decarbonisation is not just a technological challenge; it is a cultural challenge that reconstructs our notions of what constitutes normal, expected travel and communications behaviour. Will we return to relatively inexpensive, widespread flight 
where 1 per cent of the world's population emits half of the flight-related emissions (Gössling \& Humpe, 2020)? Or will equity and fairness considerations lead to a reassessment of such disparities?

In the end, flight travel post-COVID-19 will be seen in a new light. The combination of decarbonisation pressure and pandemic shifts in work habits provides an opportunity to redefine academia away from flyout culture and towards a renewed culture free from carbon pollution and compatible with a stable, liveable climate.

\section{References}

Academic Flying. (2015). Press release for public launch of petition-October 19, 2015. Flying Less: Reducing Academia's Carbon Footprint. https://web. archive.org/web/20200814044825/https://academicflyingblog.wordpress. $\mathrm{com} / 2015 / 10 / 19 /$ press-release-for-public-launch-of-petitionoctober-19-2015/

Achten, W. M. J., Almeida, J., \& Muys, B. (2013). Carbon footprint of science: More than flying. Ecological Indicators, 34, 352-355. https://doi. org/10.1016/j.ecolind.2013.05.025

Anderson, K. (2014). Slow and low-The way to go: A systems view of travel emissions. In C. Watson (Ed.), Beyond flying: Rethinking air travel in a globally connected world (pp. 68-82). Greenbooks.

Arsenault, J., Talbot, J., Boustani, L., Gonzalès, R., \& Manaugh, K. (2019). The environmental footprint of academic and student mobility in a large researchoriented university. Environmental Research Letters, 14(9), 095001. https:// doi.org/10.1088/1748-9326/ab33e6

Barish, R. J., \& Dilchert, S. (2010). Human resource responsibilities: Frequent flyer radiation exposure. Employee Responsibilities and Rights Journal, 22(4), 361-369. https://doi.org/10.1007/s10672-010-9159-6

Bazerman, M. H., \& Hoffman, A. (2000). Sources of environmentally destructive behavior: Individual, organizational and institutional perspectives. Research in Organizational Behavior, 21, 39-79. https://doi.org/10.2139/ ssrn.2940342

Beck, U. (2002). The cosmopolitan society and its enemies. Theory, Culture \& Society, 19(1-2), 17-44. https://doi.org/10.1177/026327640201900101

Berkowitz, H., \& Delacour, H. (2020). Sustainable academia: Open, engaged, and slow science. Management (France), 23(1), 1-3. https://doi.org/10.37725/ mgmt.v23.4474 
Bond, P. (2017). Al Gore's electric bills get criticism ahead of 'An Inconvenient Sequel.' Hollywood Reporter. https://www.hollywoodreporter.com/news/ al-gores-electric-bills-get-criticism-an-inconvenient-sequel-1026228

Burtscher, L., Barret, D., Borkar, A. P., Grinberg, V., Jahnke, K., Kendrew, S., Maffey, G., \& McCaughrean, M. J. (2020). The carbon footprint of large astronomy meetings. Nature Astronomy, 4(9), 823-825. https://doi. org/10.1038/s41550-020-1207-z

Chai, S., \& Freeman, R. B. (2019). Temporary colocation and collaborative discovery: Who confers at conferences. Strategic Management Journal, 40(13), 2138-2164. https://doi.org/10.1002/smj.3062

Clery, D. (2020). Astronomy is-And has-A climate problem. Science, 370(6513), 153-154. https://doi.org/10.1126/science.370.6513.153

Cohen, S. A., \& Kantenbacher, J. (2020). Flying less: Personal health and environmental co-benefits. Journal of Sustainable Tourism, 28(2), 361-376. https://doi.org/10.1080/09669582.2019.1585442

Connelly, B. L., Certo, S. T., Ireland, R. D., \& Reutzel, C. R. (2011). Signaling theory: A review and assessment. Journal of Management, 37(1), 39-67. https://doi.org/10.1177/0149206310388419

Cort, T., \& Esty, D. (2020). ESG Standards: Looming challenges and pathways forward. Organization \& Environment, 33(4), 491-510. https://doi. org/10.1177/1086026620945342

Count Us In. (2020). 16 Steps | Take a step | Count Us In. https://steps. count-us-in.org/

Delmas, M. A., \& Burbano, V. C. (2011). The drivers of greenwashing. California Management Review, 54(1), 64-88. https://doi. org/10.1016/0737-6782(88)90039-2

Delmestri, G. (2018). A body for RRBM: \#sabbicycle (sabbatical on the bike). RRBM Network. https://www.rrbm.network/a-body-for-rrbm-sabbicyclesabbatical-on-the-bike-giuseppe-delmestri/

Delmestri, G. (2019). Pledge: EGOS by train (\#OS4F). Slow academics for a better world. https://delmestri.wordpress.com/2019/05/03/pledge-egosby-train-os4f/

Dolsak, N., Prakash, A. (2018, March 31). The climate change hypocrisy of jetsetting academics. HuffPost. https:/www.huffpost.com/entry/opiniondolsak-prakash-carbon-tax_n_5abe746ae4b055e50acd5c80

Duke University Office of Sustainability. (2020). Urban forestry. Urban Forestry

Sustainability | Duke. https://web.archive.org/web/20200723033313/ https://sustainability.duke.edu/offsets/projects/forestry 
Durante, E. (2016). Between insecurity and nomadism: The suitcase as symbol and object of globalization. Cuadernos De. Literatura, 20(40), 352-368. https://doi.org/10.11144/Javeriana.cl20-40.einm

Espeland, W. N., \& Sauder, M. (2007). Rankings and reactivity: How public measures recreate social worlds. American Journal of Sociology, 113(1), 1-40. https://doi.org/10.1086/517897

ETH Zurich. (2020). Academic air travel reduction and offsetting projects. Google My Maps. https://www.google.com/maps/d/viewer?mid=1v49WXCe LrpWkeQFvl2xIak8qrTvV7jGe

Fleischmann, L., \& Franklin, M. (2017). Fumes across the fence-line: The health impacts of air pollution from oil \& gas facilities on African American communities. NAACP, Clean Air Task Force. https://www.naacp.org/climate-justiceresources/fumes-across-fence-line

Gersick, C. J. G. (1994). Pacing strategic change: The case of a new venture. Academy of Management Journal, 37(1), 9-45. https://doi.org/ $10.5465 / 256768$

Gifford, R. (2011). The dragons of inaction: Psychological barriers that limit climate change mitigation and adaptation. American Psychologist, 66(4), 290-302. https://doi.org/10.1037/a0023566

Gössling, S., \& Humpe, A. (2020). The global scale, distribution and growth of aviation: Implications for climate change. Global Environmental Change, 65, 102194. https://doi.org/10.1016/j.gloenvcha.2020.102194

Haas, M. (2019). Google summit on climate change attended by stars in private jets, mega yachts slammed as 'hypocritical'. Fox News. https://www.foxnews. com/entertainment/google-summit-attended-by-hollywood-starsslammed-as-hypocritical

Higham, J. E. S., \& Font, X. (2020). Decarbonising academia: Confronting our climate hypocrisy. Journal of Sustainable Tourism, 28(1), 1-9. https://doi. org/10.1080/09669582.2019.1695132

Hoffman, A. J. (2000). Competitive environmental strategy: A guide to the changing business landscape. Island Press.

Hoffman, A. J. (2001). Linking organizational and field-level analyses: The diffusion of corporate environmental practice. Organization \& Environment, 14(2), 133-156. https://doi.org/10.1177/1086026601142001

Hoffman, A. J. (2016, March 31). Eco-authenticity: Advocating for a lowcarbon world while living a high-carbon lifestyle. The Conversation. https:// web.archive.org/web/20200216145839/https://theconversation.com/ eco-authenticity-advocating-for-a-low-carbon-world-while-living-a-highcarbon-lifestyle-56893 
Høyer, K. G. (2009). A conference tourist and his confessions: An essay on a life with conference tourism, aeromobility and ecological crisis. Tourism and Hospitality Planning \& Development, 6(1), 53-68. https://doi. org/10.1080/14790530902847061

Høyer, K. G., \& Naess, P. (2001). Conference tourism: A problem for the environment, as well as for research? Journal of Sustainable Tourism, 9(6), 451-470. https://doi.org/10.1080/09669580108667414

IFRS Foundation. (2020). IFRS Foundation Trustees consult on global approach to sustainability reporting. https://www.ifrs.org/news-and-events/2020/09/ifrsfoundation-trustees-consult-on-global-approach-to-sustainability-reporting/

Janisch, T., \& Hilty, L. (2017). Changing university culture towards reduced air travel: Background report for the 2017 virtual conference on university air miles reduction. https://doi.org/10.5167/uzh-142121

Katz, J. K. C. (2012, June 4). Pollution, poverty and people of color: Living with industry. Scientific American. https://www.scientificamerican.com/article/pollution-poverty-people-color-living-industry/

Katz-Rosene, R. M. (2020). A not-so-green choice? The high carbon footprint of long-distance passenger rail travel in Canada. The Canadian Geographer / Le Géographe Canadien, 65(2), 141-151. https://doi.org/10.1111/cag.12649

Kedward, K., Ryan-Collins, J., \& Chenet, H. (2020). Managing nature-related financial risks: A precautionary policy approach for central banks and financial supervisors [Working Paper]. https://www.ucl.ac.uk/bartlett/public-purpose/ publications/2020/aug/managing-nature-related-financial-risks

Klöwer, M., Hopkins, D., Allen, M., \& Higham, J. (2020). An analysis of ways to decarbonize conference travel after COVID-19. Nature, 583(7816), 356-359. https://doi.org/10.1038/d41586-020-02057-2

Kotchen, M. J. (2009). Offsetting green guilt. Stanford Social Innovation Review, Spring. https://ssir.org/articles/entry/offsetting_green_guilt

Kuhn, T. (1962). The structure of scientific revolutions. University of Chicago Press. Lassen, C. (2006). Aeromobility and work. Environment and Planning A-Economy and Space, 38(2), 301-312. https://doi.org/10.1068/a37278

Lassen, C. (2009). Networking, knowledge organizations and aeromobility. Geografiska Annaler Series B-Human Geography, 91B(3), 229-243. https:// doi.org/10.1111/j.1468-0467.2009.00317.x

Le Quéré, C., Jackson, R. B., Jones, M. W., Smith, A. J. P., Abernethy, S., Andrew, R. M., De-Gol, A. J., Willis, D. R., Shan, Y., Canadell, J. G., Friedlingstein, P., Creutzig, F., \& Peters, G. P. (2020). Temporary reduction in daily global CO2 emissions during the COVID-19 forced confinement. Nature Climate Change, 10(7), 647-653. https://doi.org/10.1038/ s41558-020-0797-x 
Marchese, D. (2020). Greta thunberg hears your excuses. she is not impressed. The New York Times. https://www.nytimes.com/interactive/2020/11/02/ magazine/greta-thunberg-interview.html

McGovern, G. (2020). The hidden pollution cost of online meetings. Gerry McGovern. https://web.archive.org/web/20201007164449/https:/gerrymcgovern.com/the-hidden-pollution-cost-of-online-meetings/

Munshi, D., \& Kurian, P. (2005). Imperializing spin cycles: A postcolonial look at public relations, greenwashing, and the separation of publics. Public Relations Review, 31(4), 513-520. https://doi.org/10.1016/j. pubrev.2005.08.010

Nature Astronomy. (2020). The climate issue. Nature Astronomy, 4(9), 811-811. https://doi.org/10.1038/s41550-020-01216-9

Nature Nanotechnology. (2019). Scientists should explore alternatives to flying. Nature Nanotechnology, 14(9), 813. https://doi.org/10.1038/s41565-019-0546-3

Nursey-Bray, M., Palmer, R., Meyer-Mclean, B., Wanner, T., \& Birzer, C. (2019). The fear of not flying: Achieving sustainable academic plane travel in higher education based on insights from South Australia. Sustainability, 11(9), 2694. https://doi.org/10.3390/su11092694

Oppenheimer, M. (2014, December 5). Setting aside a scholarly get-together, for the planet's sake, The New York Times. https://web.archive.org/ web/20191203232559/https://www.nytimes.com/2014/12/06/us/settingaside-a-scholarly-get-together-for-the-planets-sake.html

Oreskes, N., \& Conway, E. (2011). Merchants of doubt: How a handful of scientists obscured the truth on issues from tobacco smoke to global warming. Bloomsbury.

Parsons, D. (2009). The environmental impact of engineering education in Australia. The International Journal of Life Cycle Assessment, 14(2), 175-183. https://doi.org/10.1007/s11367-008-0045-5

Quito, A. (2018). Every Google search results in $\mathrm{CO}_{2}$ emissions. This real-time data viz shows how much. Quartz. https://web.archive.org/ web/20200607063612/https:/qz.com/1267709/every-google-search-resultsin-co2-emissions-this-real-time-dataviz-shows-how-much/

Romanelli, E., \& Tushman, M. L. (1994). Organizational transformation as punctuated equilibrium: An empirical test. Academy of Management Journal, 37(5), 1141-1166. https://doi.org/10.5465/256669

Ruddick, S. (2019). Slow conferencing. ACME: An International Journal for Critical Geographies, 18(3), 576-580. 
Schein, E. H. (1990). Organizational culture. American Psychologist, 45(2), 109-119. https://doi.org/10.1037/0003-066X.45.2.109

Schein, E. H. (2010). Organizational culture and leadership. John Wiley \& Sons. Sparkman, G., \& Attari, S. Z. (2020). Credibility, communication, and climate change: How lifestyle inconsistency and do-gooder derogation impact decarbonisation advocacy. Energy Research \& Social Science, 59. https://doi. org/10.1016/j.erss.2019.101290

Stay Grounded. (2020). Home. Stay Grounded. https://stay-grounded.org/

Stenhouse, N., \& Heinrich, R. (2019). Breaking negative stereotypes of climate activists: A conjoint experiment. Science Communication, 41(3), 339-368. https://doi.org/10.1177/1075547019848766

Stevens, A. R. H., Bellstedt, S., Elahi, P. J., \& Murphy, M. T. (2020). The imperative to reduce carbon emissions in astronomy. Nature Astronomy, 4(9), 843-851. https://doi.org/10.1038/s41550-020-1169-1

Stockton, N. (2015). The Paris climate talks will emit 300,000 tons of $\mathrm{CO}_{2}$, by our math. Hope it's worth it | WIRED. https://web.archive.org/ web/20200626230714/https:/www.wired.com/2015/11/the-paris-talks-couldproduce-300000-tons-of-co2-hope-theyre-worth-it/

Tapper, J. (2007). Al Gore's inconvenient truth'?-A $\$ 30,000$ utility bill. ABCNews. https://abcnews.go.com/Politics/GlobalWarming/story?id=2906888\&page=1

Union of Concerned Scientists. (2020). Each country's share of $\mathrm{CO}_{2}$ emissions. https://web.archive.org/web/20201012023621/https://www.ucsusa.org/ resources/each-countrys-share-co2-emissions

Urry, J. (2002). Mobility and proximity. Sociology, 36(2), 255-274. https://doi. org/10.1177/0038038502036002002

Whitaker, J., New, R., \& Ireland, D. (2016). MOOCs and the online delivery of business education: What's new? What's not? What now? Academy of Management Learning \& Education, 15(2). https://doi.org/10.5465/ amle.2013.0021

Worrall, E. (2015). Climate activist: Flying to conferences lacks integrity. Watts up with that? https://web.archive.org/web/20201005122945/https://wattsupwiththat.com/2015/10/03/climate-activist-flying-to-conferenceslacks-integrity/

Wynes, S., Donner, S. D., Tannason, S., \& Nabors, N. (2019). Academic air travel has a limited influence on professional success. Journal of Cleaner Production, 226, 959-967. https://doi.org/10.1016/j.jclepro.2019.04.109 
Open Access This chapter is licensed under the terms of the Creative Commons Attribution 4.0 International License (http://creativecommons.org/licenses/ by/4.0/), which permits use, sharing, adaptation, distribution and reproduction in any medium or format, as long as you give appropriate credit to the original author(s) and the source, provide a link to the Creative Commons licence and indicate if changes were made.

The images or other third party material in this chapter are included in the chapter's Creative Commons licence, unless indicated otherwise in a credit line to the material. If material is not included in the chapter's Creative Commons licence and your intended use is not permitted by statutory regulation or exceeds the permitted use, you will need to obtain permission directly from the copyright holder.

(c) (1) 